Randomised controlled trial

\section{Are E-cigarettes more effective in supporting smoking cessation than nicotine-replacement therapy?}

10.1136/ebnurs-2019-103132

Check for updates

Myriam Cadet

Bronx Community College, New York City, New York, USA

Correspondence to: Myriam Cadet, Bronx Community College, New York city, NY 10453, USA; myriamjeancadet@yahoo.com

Commentary on: Hajek P, Phillips-Waller A, Przulj D, et al. A randomized trial of $E$-cigarettes versus nicotine-replacement therapy. N Engl J Med 2019;380:629-37. doi: 10.1056/ NEJMoa1808779.

\section{Commentary: implication for research and practice}

- Nurses need to design evidence-based research studies on the prevention of smoking using e-cigarettes or nicotine-replacement therapy to improve health.

- Nurses should support patients' treatment preferences and values, based on evidence-based practice guidelines for smoking cessation.

\section{Context}

A total of 34.3 million people are smokers in the USA. ${ }^{1}$ Smoking leads to disease, disability and harms to nearly every organ of the body. ${ }^{1}$ Treating smoking addictions has received a great deal of attention in recent years, but there is limited evidence on the effectiveness of smoking cessation treatments using e-cigarettes versus nicotine-replacement therapy. ${ }^{2}$

\section{Methods}

Eight hundred and eighty-six participants underwent randomisation by assigning two groups from the UK National Health Service in three sites. Participants were provided for 3 months with either an e-cigarette starter pack (a second-generation refillable e-cigarette with one bottle of nicotine e-liquid $(18 \mathrm{mg} / \mathrm{mm})$ ) or a nicotine-replacement product of their choice. Weekly behavioural support was also provided to participants for at least 4 weeks. The primary outcomes of the study were to sustain abstinence, which was validated biochemically using carbon monoxide levels of $<8 \mathrm{ppm}$ at 1 year at the last visit. ${ }^{2}$ Those who did not provide biochemical validations and missed follow-up visits were not considered to be abstinent. Other outcomes of the study were for participants to report respiratory symptoms and treatment usage.

\section{Findings}

The study findings revealed 18\% abstinence in the e-cigarettes group, compared with 9.9\% in the nicotine-replacement group. Mouth irritation or throat irritation was reported more frequently in the e-cigarette group (65.3\% vs $51.2 \%$ in the nicotine-replacement group). However, nausea symptoms were more commonly reported in the nicotine-replacement therapy group (37.9\% vs 31.3\% in the e-cigarette group). Cough and phlegm incidence declined in the e-cigarette group as compared with the nicotine group. For wheezing and shortness of breath incidence, no significant differences were found between the two groups. E-cigarettes were rated to provide greater satisfaction to participants as compared with nicotine-replacement products.

\section{Commentary}

The study focused on the effectiveness of e-cigarettes and nicotinereplacement therapy to facilitate smoking cessation and support abstinence. This study is crucial for nurses when caring for patients because tobacco addictions are a severe public health issue. ${ }^{3}$ The nurse's role is to promote the shared decision-making process, plan behavioural interventions to stop smoking and develop smoking prevention strategies to prevent health complications and maintain abstinence.

Within the study, the effectiveness of treatment on abstinence rates was higher in the e-cigarettes group as compared with the nicotine-replacement group. ${ }^{2}$ Also, treatment adherence was similar in both groups of research participants; but e-cigarettes were found to be used more frequently and for a longer period of time when compared with nicotine-replacement products. Another strategy to maintain abstinence from smoking cessation is using behavioural therapies. To quit smoking, a patient can learn new and effective behaviours to help with smoking addictions. E-cigarettes were more effective for smoking cessation as compared with nicotine-replacement treatment when used together with behavioural support. ${ }^{2}$ The nurse can develop behavioural support interventions to help a patient adhere to smoking cessation treatment using e-cigarettes. Quitting smoking can be a difficult decision; therefore, using behavioural therapies and e-cigarettes as adjunctive treatment can support smoking cessation, stop the urge of smoking and prevent further addictions. ${ }^{4}$

Smoking cessation can be promoted at different levels of prevention. In primary prevention, the nurse can teach patients about behavioural lifestyle changes to prevent the use of cigarettes. Secondary prevention can focus on screening smokers; tertiary prevention assesses for long-term treatment adherence to quit smoking by assessing barriers to quit smoking, evaluating previous attempts to quit smoking, assessing willingness to quit smoking and evaluating the patients' preferences of treatment and values. ${ }^{13}$

Smoking cessation is critical to addressing a global public health issue. This study provides nurses with an insight into those methods that can best support effective, individualised approaches to promoting cessation and abstinence.

Funding The authors have not declared a specific grant for this research from any funding agency in the public, commercial or not-for-profit sectors.

Competing interests None declared.

Patient consent for publication Not required.

Provenance and peer review Commissioned; internally peer reviewed.

๑ Author(s) (or their employer(s)) 2020. No commercial re-use. See rights and permissions. Published by BMJ.

\section{References}

1. Centers for Disease Control and Prevention. Smoking and tobacco use. Fast facts and fact sheets, 2019. Available: https://www.cdc.gov/tobacco/data_statistics/fact_ sheets/index.htm

2. Hajek P, Phillips-Waller A, Przulj D, et al. A randomized trial of e-cigarettes versus nicotine-replacement therapy. N Engl J Med 2019;380:629-37.

3. Cadet MJ. Cigarette smoking cessation involving the 5-A framework. Workplace Health Saf 2018;66:312-3.

4. Gomajee R, El-Khoury F, Goldberg M, et al. Association between electronic cigarette use and smoking reduction in France. JAMA Intern Med 2019. doi:10.1001/ jamainternmed.2019.1483. [Epub ahead of print: 15 Jul 2019]. 